\title{
USE OF BIM APPROACH TO ENHANCE CONSTRUCTION INTERFACE MANAGEMENT: A CASE STUDY
}

\author{
Yu-Cheng LIN \\ Department of Civil Engineering, National Taipei University of Technology, \\ No. 1. Chung-Hsiao E. Rd., Sec. 3, Taipei, Taiwan, R.O.C.
}

Received 27 May 2012; accepted 22 Oct 2012

\begin{abstract}
Many interface events and problems occur during the construction phase of construction projects, such that tracking and controlling these are essential to construction management. Interface management (IM) has become the most important aspect of a sound project management strategy. IM affects project cost, scheduling, and quality both directly and indirectly in construction projects. Interface or changed events can be identified and tracked using IM, such that construction processes can be improved, while minimizing rework and reducing total project duration. Despite the many studies and discussions in academic and practical literature, systematic approaches and information platforms for managing interface events and problems during the construction are lacking. This study tracks and manages interface events using novel three-dimensional (3D) interface maps integrated into the building information modelling (BIM) approach. The BIM approach, which is utilized to retain interface information in a digital format, facilitates easy interface updating and transfer in the 3D CAD environment. The 3D-based interface maps provide users with an overview of interface events during a given construction project, such that users can track and manage interfaces virtually. The primary purpose of this study is to develop a web Construction BIM-based IM (ConBIM-IM) system for engineers to enhance interface information sharing and efficiency tracking in construction projects. The ConBIM-IM system is applied to a case study of a building project in Taiwan to verify its efficacy and demonstrate its IM effectiveness. Case study results show that the ConBIM-IM system is effective for managing interfaces using the BIM approach in construction.
\end{abstract}

Keywords: interface management, BIM, building information modelling, information system, web-based system, construction management.

\section{Introduction}

Construction projects, which are characterized by extreme complexity and non-standardized production, differ in that each is designed and executed to meet individual owner needs (Clough et al. 2000). Thus, effectively managing project interfaces is essential to successful construction management (Chua, Myrian 2006). Effectively tracking and managing interfaces can improve interface management (IM) in construction, thereby eliminating unnecessary mistakes. Effective interface information sharing allows project participants to identify existing interfaces and solve interface problems. Without IM, poorly coordinated and controlled boundary conditions among project participants can cause such interface problems as design errors, part mismatch, system performance failures, coordination difficulties, and construction conflicts (Clough et al. 2000). Conventional interface communication methods include face-to-face meetings, telephone communication, and virtual design and construction (VDC). However, a typical problem encountered during conventional communication is that discussions may not be effectively tracked and shared with others (Siao et al. 2009).
Construction projects, which typically involve participants from different fields, often have numerous interface problems. Interface information regarding the needs and progress status of each project participant is generally not transmitted effectively from one service provider to another, or effectively exchanged among project participants (Siao, Lin 2012). Moreover, participants frequently execute their own work and rarely share interface information (Siao et al. 2009). Face-to-face meetings and telephone communication are common and practical methods for project participants to share interface information during the construction phase. Despite many studies and discussions in academic and practical literature, systematic approaches and information platforms for managing interface events and problems during construction are lacking. IM is currently not widely applied in the construction industry because construction project management programs do not support the needed functionality. Additionally, no appropriate platforms exist that assist project participants in tracking and managing interface information during the construction phase.

Corresponding author: Yu-Cheng Lin

E-mail:yclin@ntut.edu.tw 
Building information modelling (BIM) is a new industry term referring to parametric $3 \mathrm{D}$ computer-aided design (CAD) technologies and processes in the AEC industry. During the construction phase, participants typically execute their own work and rarely share interface information with other participants. IM is an information-intensive task in which extremely useful information is made available to participants. In order to assist engineers in exchanging and sharing interface information, the primary objective of this study is to facilitate interface sharing and management during the construction phase. Identifying, tracking, controlling, and managing interface events and problems are critical tasks in IM. This study develops the ConBIM-IM system for engineers to enhance interface information sharing and tracking efficiency. Notably, this study integrates novel 3D interface maps and the BIM approach to track and manage interfaces in a graphic form. The main function of the BIM approach in this study is 3D illustration and mapping of interfaces. The BIM approach retains interface information in a digital format and facilitates easy updating and transfer of interface information in the 3D CAD environment. By using the 3D interface maps, project participants can obtain an overview of previous and current interface events in a given project and manage interfaces. Furthermore, project participants can track and access the most recent information for any interface, change, or conflict during the construction phase. Interfaces can be updated rapidly and made available to each participant via the 3D CAD environment during the construction phase. This research is a pilot study to apply the ConBIM-IM system for IM during a building project in Taiwan and analyses and discusses the entire IM process.

The paper is structured as follows. The current state of IM during the construction phase and need for a BIMbased IM system is addressed at the beginning of this paper. The related literature review is presented in Section 1. Section 2 presents information on the technologies, BIM tools, and IM approach used in this study. Section 3 contains the implementation for the proposed ConBIM-IM system for IM. A case study is presented in Section 4. The results demonstrate the benefits of the developed ConBIM-IM system in assisting involved project participants handle IM work processes efficiently. The final section summarizes the main conclusions.

\section{Literature review}

Interface management in construction affects the cost, the scheduling, and the quality of projects, both directly and indirectly. The interfaces can be identified and tracked in interface management by involving the general contractor and all participants to improve the construction process while simultaneously minimizing deleterious change and promoting beneficial change. Limited research has examined interface management issues in construction: (1) Al-Hammand (2000) proposed 19 common interface problems identified based on four categories (financial problems, inadequate contract, specification, and environmental problems); (2) Chan et al. (2005) suggested an interface management framework for China's BOT projects; (3) Chua and Myrian (2006) proposed a workbreakdown structure (WBS) concept for improving work interface management; (4) Pavitt and Gibb (2003) used CladdISS tool to process maps, action plans, management strategy, and interface management; (5) Chen et al. (2007) illustrated how IM can help with the application of agile project management and Lean construction; (6) Chen et al. (2008) proposed a multi-perspective approach for systematically exploring comprehensive cause factors affecting various interface issues; (7) Chen et al. (2010) presented an interface object modelling technique and interface object model framework for improving interface-related project performance; (8) Senthilkumar et al. (2010) developed a web-based system for IM for construction projects during the design phase; (9) Siao and Lin (2012) presented a multilevel interface matrix approach to enhance interface management in construction; (10) Shokri et al. (2012) proposed a process based approach and system for interface management of mega capital projects.

BIM is one of the most promising recent developments in the AEC industry (Azhar 2011). BIM was introduced nearly ten years ago to provide an environment where any related information on $3 \mathrm{D}$ entity models could be retrieved during the project life cycle (Tse et al. 2005; Ding et al. 2012). BIM is believed to be essential in AEC to manage, share and exchange information among project stakeholders, such as architects, engineers, contractors, owners and subcontractors (Fu et al. 2006). BIM technologies are being adopted more slowly in the AEC industry than 2D CAD (Whyte et al. 1999, 2002). BIM assists construction planners in making crucial decisions by enabling visualization of the details of the prospective work (Chau et al. 2004). BIM is a new technology in the field of CAD, which contains not only geometric data, but also a great amount of engineering data through the lifecycle of a building (Xudong, Jie 2007). BIM is a new industry term referring to parametric $3 \mathrm{D}$ computeraided design (CAD) technologies and processes in the AEC industry (Taylor et al. 2009). BIM is a digital tool that supports continual updating and sharing of project design information (Gould, Joyce 2008). A BIM system enables users to integrate and reuse building information and domain knowledge throughout the lifecycle of a building (Eddy, Bradley 2008). A BIM is a computable representation of all of a building's physical and functional characteristics and related lifecycle information, and is a repository of information for building owners and operators and used and maintained throughout the lifecycle of a building (Manning, Messner 2008).

Several definitions of BIM are proposed in prior research. According to the National Building Information Modeling Standard Committee, a building information 
model (BIM) is defined as "a digital representation of physical and functional characteristics of a facility. As such it serves as a shared knowledge resource for information about a facility forming a reliable basis for decisions during its lifecycle from inception onward" (National Building Information Modeling Standard 2007). BIM digitally contains precise geometry and relevant data needed to support the design, procurement, fabrication, and construction activities to describe 3D object-oriented CAD (Eastman et al. 2008). BIM is an additional model for engineering information database, storing all the architectural design with geometric information and the corresponding technical information of all the works (Ding et al. 2012). BIM supports the automatic evaluation of building design, rather than the manual, iterative and time-consuming evaluation of CAD drawings (Lee et al. 2012c). The complete building model and all of its representations are included in the single BIM file. Furthermore, changes made in the BIM model will affect all related drawings and data automatically. BIM modelling enables the users to generate and update project documents automatically and building information data are attached to the elements (Eastman et al. 2008). Advanced analysis using the BIM modelling allows a wide range of analytical applications such as code checking, collision detection, energy efficiency analysis, structural analysis and simulation.

There are much previous researches have examined BIM issues in construction. There are many core benefits, barriers, framework and recommends of BIM cited in the previous work in supporting decisions and improving processes throughout the lifecycle of a project (Tse et al. 2005; Eastman et al. 2008; Shen, Issa 2010; Manning, Messner 2008; Succar 2009; Becerik-Gerber, Rice 2010; Jung, Joo 2011; Barlish, Sullivan 2012). Related to the design phase of a project, these topics include parametric modelling, BIM at different level of detail (LoD), identification of design conflicts and analysis, green design, design simulation, cost estimation, and accurate geometric representation of all facilities (Li et al. 2006; Leite et al. 2011; Eastman et al. 2008; Kaner et al. 2008; Shen, Issa 2010; Staub-French, Khanzode 2007; Manning, Messner 2008; Fox, Hietanen 2007; Schlueter, Thesseling 2009; Isikdag, Underwood 2010; Shen et al. 2012; Lee et al. 2012a, b, c). During the construction phase, these benefits include less rework, reduction in requests for information and change orders, customer satisfaction through visualization, improved productivity in phasing and scheduling, faster and more effective construction management with easier information exchange, accurate cost estimation, and visualizing safety analysis (Eastman et al. 2008; Hardin 2009; Matta, Kam 2010; Elbeltagi, Dawood 2011; Azimi et al. 2011; Azhar 2011; Zhou et al. 2012; Hartmann et al. 2012). During the operation phase, these benefits will include control of facilities management progress, integrated life-cycle data, rapid and accurate information of updating and changing activities, more effective facility management with easier information exchange (Eastman et al. 2008; Hardin 2009; Staub-French, Khanzode 2007; Manning, Messner 2008; Underwood, Isikdag 2010; CRC 2010; Klein et al. 2012). Regarding to education, there are many previous researches present the effectiveness of $\mathrm{BIM}$ as an integrated learning tool in construction education (Eastman et al. 2008; Becerik-Gerber, Kensek 2010; Sacks, Barak 2010). Regarding to information system development, there are many previous researches present the application of proposed system integrated with BIM in construction (Vanlande et al. 2008; Dossick, Neff 2010; Jardim-Goncalves, Grilo 2010; Redmond et al. 2012; Ren et al. 2012). Furthermore, there are many previous researches regarding to data exchanges of BIM models (Goedert, Meadati 2008; Jeong et al. 2009; Sacks et al. 2010).

Despite many articles and system developments in academic and practice literature, there is a lack of systematic approaches and 3D visual information platforms to track and manage interface events and problems during the construction phase. To solve this problem, the proposed web Construction BIM-based Interface Management (ConBIM-IM) system is developed to enhance interface information sharing and tracking efficiency. Furthermore, this study integrates BIM into the construction process and applies the BIM approach for construction IM (Fig. 1). The BIM approach, which is applied to retain interface information in a digital format, facilitates easy updating and transfer of interfaces in a $3 \mathrm{D}$ CAD environment. This study manages interfaces using novel 3D interface maps integrated with the BIM approach. By using these 3D-based interface maps, users can acquire a process overview, solve interface problems, and manage interfaces during the construction phase. Finally, the proposed ConBIM-IM system is applied to a case study of a building project in Taiwan to verify its efficacy and demonstrate its IM effectiveness.

\section{Research method - BIM-based interface management}

Interface management is now recognized as the most critical organizational strategy in construction management (Siao et al. 2009). Interface management is the systematic control of communications that support process operations (Healy 1997). As an outgrowth of the influences of system-based thinking in project management, IM addresses project complexity and allows for a dynamic and well-coordinated construction project system (Chen et al. 2007). Despite the many academic studies and extensive discussions in practice, construction professionals lack systematic approaches for managing interfaces during construction and assembly phases (Evans et al. 1997). According to construction project interfaces questionnaire survey results (Lin 2009), the primary interface problems encountered during the construction 


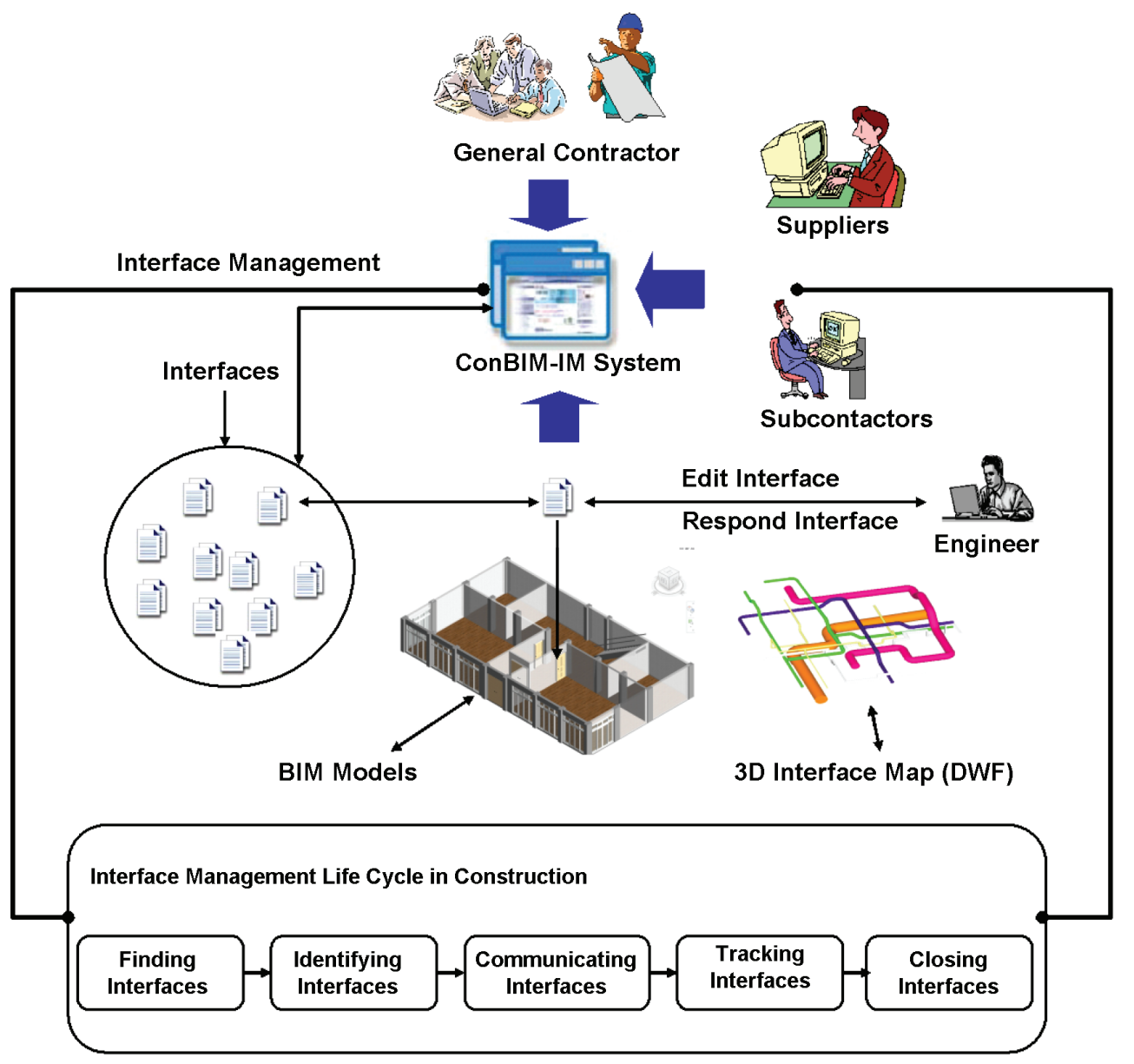

Fig. 1. The application of ConBIM-IM system in construction IM

phase in Taiwan are as follows: (1) insufficient platforms/ functions supporting IM for construction project management; (2) failure to properly manage conflicts and interfaces; (3) many interface conflicts related to time, space, issues, and organizations must be handled during the construction phase; (4) an ineffective mechanism for tracking and managing interfaces during the construction phase; (5) no official and complete record of interfaces and communication among participants; (6) few suitable platforms to assist participants in sharing interface information when needed; and, (7) difficulty tracking interface events and obtaining interface information from other participants.

The interface can be identified and tracked in interface management by involving all participants to improve operation management, minimize deleterious change, and promote beneficial change. There are many categories relating to construction interfaces in the literature. Morris (1983) argued that there are two interfaces-static interfaces and dynamic interfaces. Stuckenbruck (1983) identified three main interfaces-personal interfaces, organizational interfaces and system interfaces. Healy (1997) proposed four main interfaces-time interfaces, geographic interfaces, technical interfaces and social interfaces. Laan et al. (2000) identified three main interfaces-functional interfaces, physical interfaces and organizational interfaces. Pavitt and Gibb (2003) proposed three main interface types: physical interfaces, contractual interfaces and organizational interfaces. This study focuses on problem interfaces during the construction phase - constructability problems interfaces, process problems interfaces, space and conflict problems interfaces, communication problems interfaces, and variability problems interfaces. Moreover, the proposed IM procedure encompasses finding interfaces, identifying interfaces, communicating interfaces, tracking interfaces, and closing interface based on literature review findings and interviews with construction professionals. Each phase is outlined briefly as follows (Table 1).

Visualization Technology has been widely adopted in construction to facilitate construction planning (Liston et al. 1998), conflicts analysis (Zhang, $\mathrm{Hu} 2011$ ), constructability reasoning (Golparvar-Fard et al. 2009) and site layout planning (Ma et al. 2005). Expression patterns of traditional information remain at the two-dimensional (2D) level. However, people's perception of the building is three-dimensional. Performance of 2D graphics is limited, especially when dealing with the shape and size of a component as well as spatial relationships between the components. BIM is a digital tool that supports 
Table 1. Description of construction IM phases

\begin{tabular}{ll}
\hline Phase & \multicolumn{1}{c}{ Description } \\
\hline Finding interfaces & Checks for new or existing project-related interface events. \\
\hline Identifying interfaces & Ensures that identified interfaces are notified to for all related participants. \\
\hline Communicating interfaces & Encompasses request, response and tracking processes among all participants. \\
\hline Tracking interfaces & Records the processes related to an identified interface event. \\
\hline Closing interfaces & $\begin{array}{l}\text { The final closing act when an interface event is confirmed without further identification or } \\
\text { tracking. }\end{array}$ \\
\hline
\end{tabular}

continual updating and sharing of project design information (Gould, Joyce 2008). BIM digitally contains precise geometry and relevant data needed to support the design, procurement, fabrication, and construction activities to describe 3D object-oriented CAD (Eastman et al. 2008). BIM-based visualization can express information more intuitively (Ding et al. 2012). It can realize real-time construction visualization. Besides, communication and discussion among all participants may be enhanced effectively by visualization (Hajdasz 2008). The use of the $3 \mathrm{D}$ object models have essentially contributed to a shared understanding of intentions, needs and geometrical relations among actors representing different backgrounds, interests and positions (Moum 2010). Furthermore, 3D modelling makes the participants mindful of accuracy and adequacy (Vainiunas et al. 2011). There are many relationships between interfaces and CAD in view of construction interface management. In order to assist engineers in discussing and managing interfaces linked within a CAD-based environment, the main purpose for conducting this research is to develop ConBIMIM system for involved engineers to facilitate interface updates and transfers within the 3D CAD environment. This study proposes a novel approach using 3D-based interface maps integrated with BIM to enhance interface information sharing and tracking efficiency in construction projects.

The application of BIM does not cease after the design phase. Notably, BIM can be used by project participants during the construction phase, allowing project participants to track project updates and rapidly update digital records of work completed during the construction phase. BIM has three main features. The first feature is that data and information about models can be stored in databases to facilitate collaboration. The second feature is that changes to these databases can be managed, such that a change in a database affects all other parts of models. The third feature is that information from a particular model can be captured and preserved for reuse by adding industry-specific applications (Vanlande et al. 2008). In this study, the proposed ConBIM-IM system facilitates interface information sharing and managing for IM during the construction phase. The BIM approach stores the original, actual, changed, and interface information, allowing all project participants to access the most recent information. Furthermore, BIM can model and promote the sharing of electronic information related to interfaces and changes with all project participants (Fig. 2). The primary advantages of BIM-based IM are as follows: (1) provides a simple and clear representation of interfaces in the 3D CAD environment; (2) illustrates available interface events for activities in construction projects; (3) can extend interface relationships as both vertical and horizontal graphic representations; and (4) BIM-based IM helps users track and identify interface events using different colours.

The proposed ConBIM-IM system is designed for construction IM. The 3D interface maps can be defined as a 3D CAD graphic representation of interface events linking relationships between $\mathrm{CAD}$ objects and attributes of interface events. The BIM approach retains interface information in a digital format, facilitating easy updates and transfer of interfaces in the 3D CAD environment. The 3D interface maps are designed to be easily integrated with interface events and CAD objects. Assisted by the 3D BIM approach, interface information in the 3D interface maps can be identified, tracked, and managed, and problems encountered during construction projects can be solved. The most recent interface problems and solutions can be acquired from participating engineers and then shared and saved as 3D CAD map units for efficient management and future reference. The proposed 3D interface maps have eight components (Fig. 3). These eight components are the ID, topic, date, description, owner, people, attachments, and history.

The 3D-based interface maps, which are defined in multiple objects, are constructed from variables that can be decomposed into 3D map units to store the identified interface. The 3D interface maps allow users to access interface information stored in layers based on interface problem attributes and type. Interface information stored in map units includes both interface problems and solutions. Interface problems may be interface event topics, interface event descriptions, descriptions of problems, or interface event attachments (e.g. documents, reports, drawings, and photographs). Interface solutions may include problem descriptions, problem explanations, previous solutions, suggested solutions, and comments. Additionally, the 3D interface maps allow users to review interface event maps for a selected project to enhance IM effectiveness. Interface problems and solutions in mapbased IM are associated with projects, activities, people, 


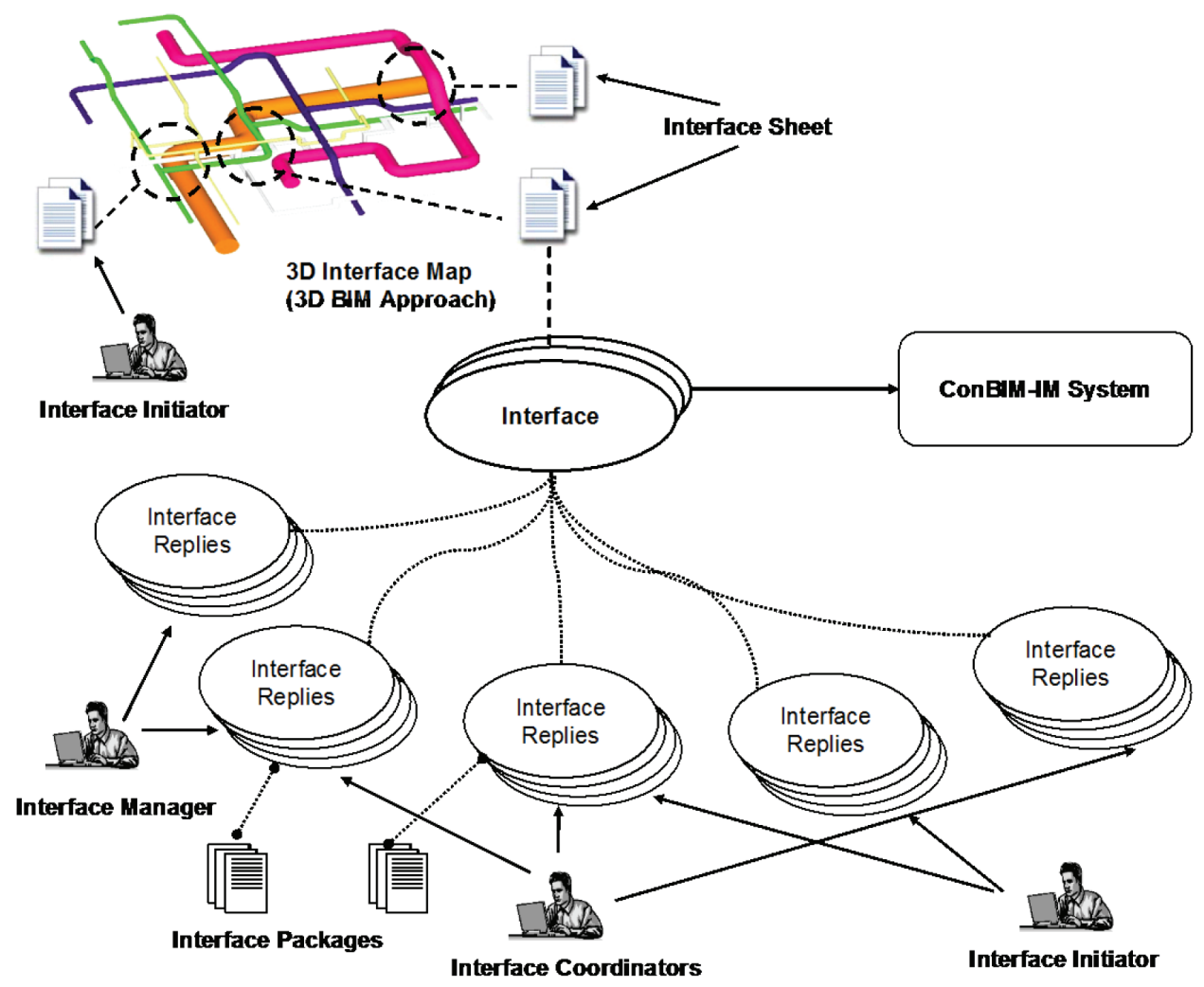

Fig. 2. Application of the BIM approach in construction interface management

and organizations. Identifying the relationships between interface events and all interface information is essential for managers and engineers when tracking and managing construction interfaces.

\section{System implementation}

\subsection{System architecture}

The conceptual model is developed to underpin the ConBIM-IM system in the study (Fig. 4). The conceptual model involves different types of interface contents that provide the flexibility of the ConBIM-IM system and make the BIM-based IM process accessible to the construction project in practice. The conceptual model of ConBIM-IM system content aims to improve the quality and effectiveness of BIM-based IM system in complex and dynamic environments. The conceptual model of the ConBIM-IM system includes data and information on related interfaces, which facilitates access to BIMbased IM work. The various interfaces appearing in the ConBIM-IM system have to be analysed and integrated, so the information can be supported by a combination of contents with the functionality. The system should support all features available in existing state-of-the-art content management and web communication tools. In addition, the database of the ConBIM-IM system includes different interface topics and contents realized by interface description, interface reply, BIM model and related attachments. All related attachments can include text, images, video data, e-documents, and BIM models. The conceptual model of 3D-based interface maps includes BIM model selection, BIM model angle setup, BIM model location setup, and BIM model mark-up colour setup. Furthermore, the 3D-based interface maps relationship content include each relationship between interface content and BIM model.

The following section describes the development of the proposed ConBIM-IM system. The developed ConBIM-IM system runs on Microsoft Windows 2003 software with an Internet Information Server (IIS) as the web server. The ConBIM-IM system is developed using Java Server Pages (JSP), which are easily incorporated with HTML and JavaScript technologies. The ConBIM-IM system server supports four distinct layers: interface, access, application and database layers (Fig. 5). Each layer has its own responsibilities. The interface layer defines administrative and end-user interfaces. Users can access information via web browsers such as Microsoft Internet Explorer or Google Chrome. Administrators control and manage information via the web browser or using a separate server interface. The access layer provides system security and restricted access, firewall services and system administration functions. The application layer defines various applications for analyzing and managing information. The database layer consists of a primary Microsoft SQL Server 2003 database. A firewall and virus scanning capability are used to protect the system database against intrusion. 


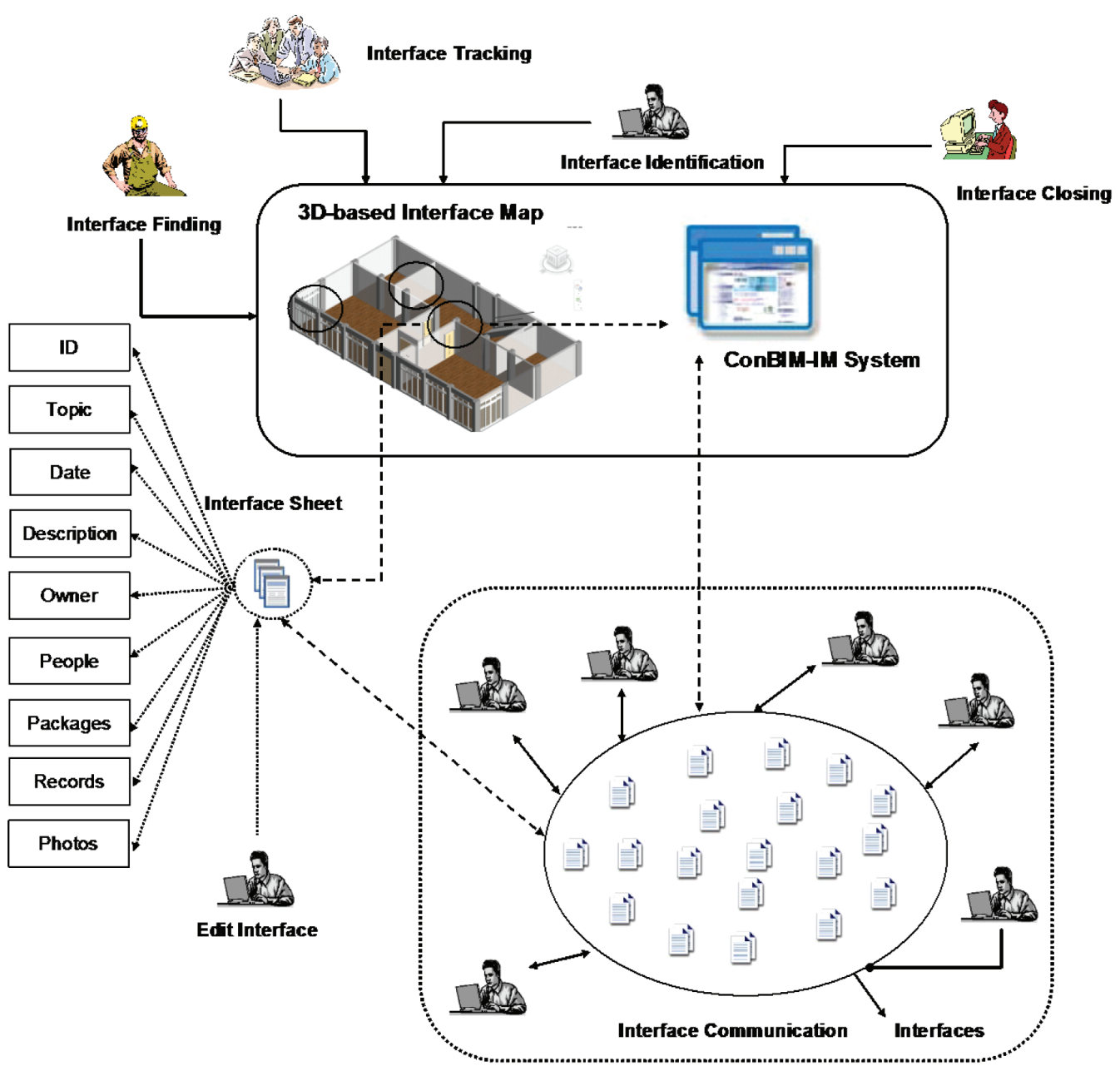

Fig. 3. The concept and framework of 3D-based interface maps approach

The ConBIM-IM system is designed for all project participants via a user-friendly portal, which serves as a real-time, on-line communication channel for project participants. All data are stored and classified using the 3D interface maps in the ConBIM-IM system. The ConBIMIM system is a solution that uses a single, unified database linked to BIM files with different levels of access determined by user roles. Only authorized participants can access the 3D interface maps for interface information entry and updates based on their responsibilities in the ConBIM-IM system. When information is updated in the ConBIM-IM system, the server automatically sends e-mails and Really Simple Syndication (RSS) feeds to the project manager and participants associated with the interface.

In this study, BIM is used as an information model in the ConBIM-IM system. One purpose is to extend BIM to the construction phase and create a single repository of interface data for all project participants. The BIM is applied in the ConBIM-IM system to capture and store interface information, including interface event descriptions, interface-related parties, interface records, and interface reports. Design Web Format (DWF) file is selected as the format of 3D interface maps file for interface markup use because DWF files that are highly compressed are smaller and faster to transmit than design files. Design Web Format (DWF) is a secure file format developed by Autodesk for the efficient distribution and communication of rich design data to anyone who needs to view, review, or print design files (Wikipedia 2012). Autodesk Revit Architecture and Revit MEP were used to model the 3D interface maps and create BIM files. Autodesk Design Review was used to read BIM DWF files of the 3 D interface maps. Information integration with the 3D interface maps was achieved using the Autodesk Revit application programming interface (API) and Microsoft Visual Basic.Net (VB.Net) programming language. The ConBIM-IM system was developed by integrating the 3D-based interface maps and interface-related information using Autodesk Revit Architecture and Revit MEP software. Visual 3Dbased interface maps (DWF file) were linked with the ConBIM-IM system by Revit API programming. A program in $\mathrm{C}++$ was written to integrate acquired data from different DWF files and all interface information, such that BIM files can be exported to an ODBC database for connection with the ConBIM-IM system. 


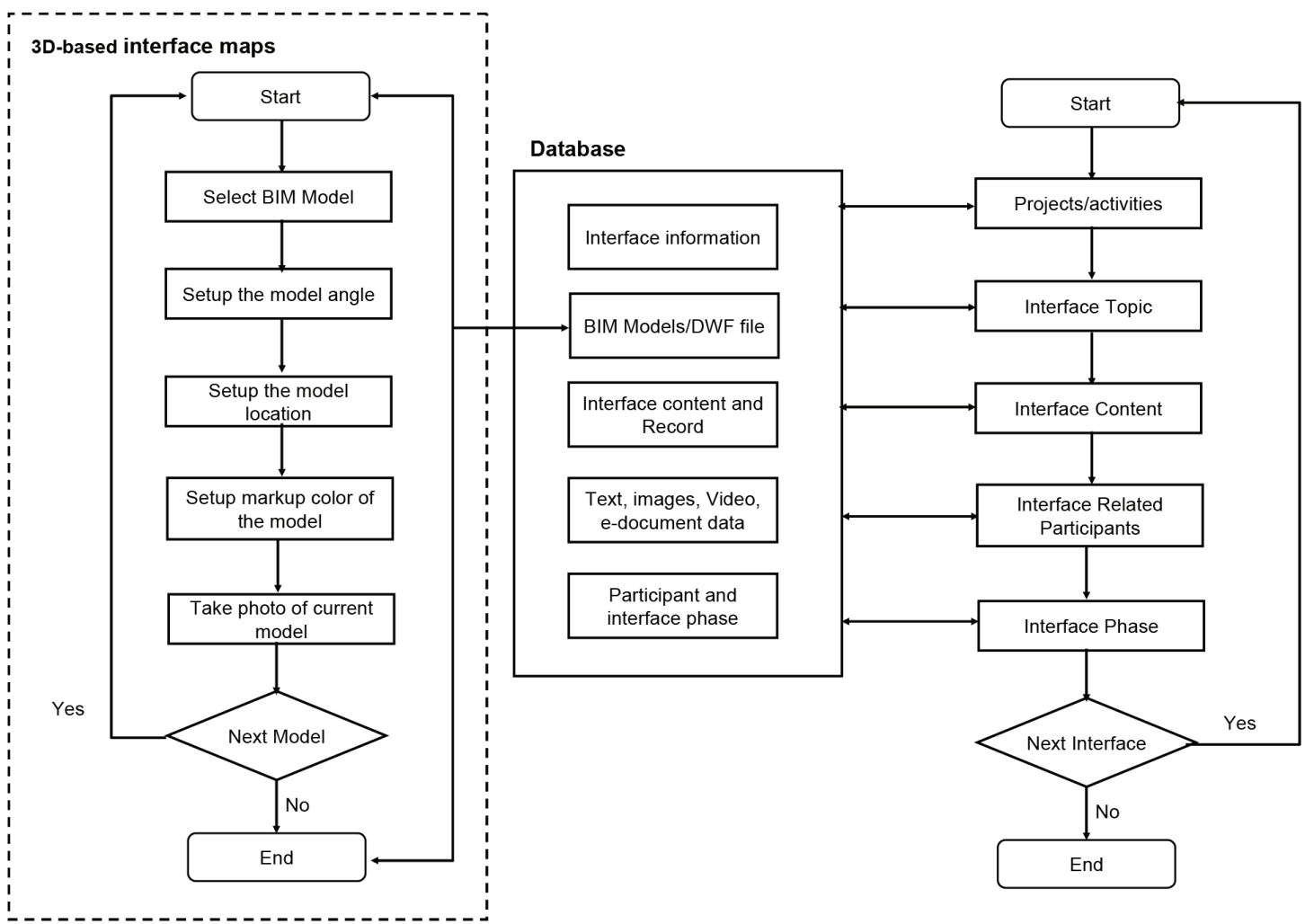

Fig. 4. A conceptual model of ConBIM-IM system

ConBIM-IM System

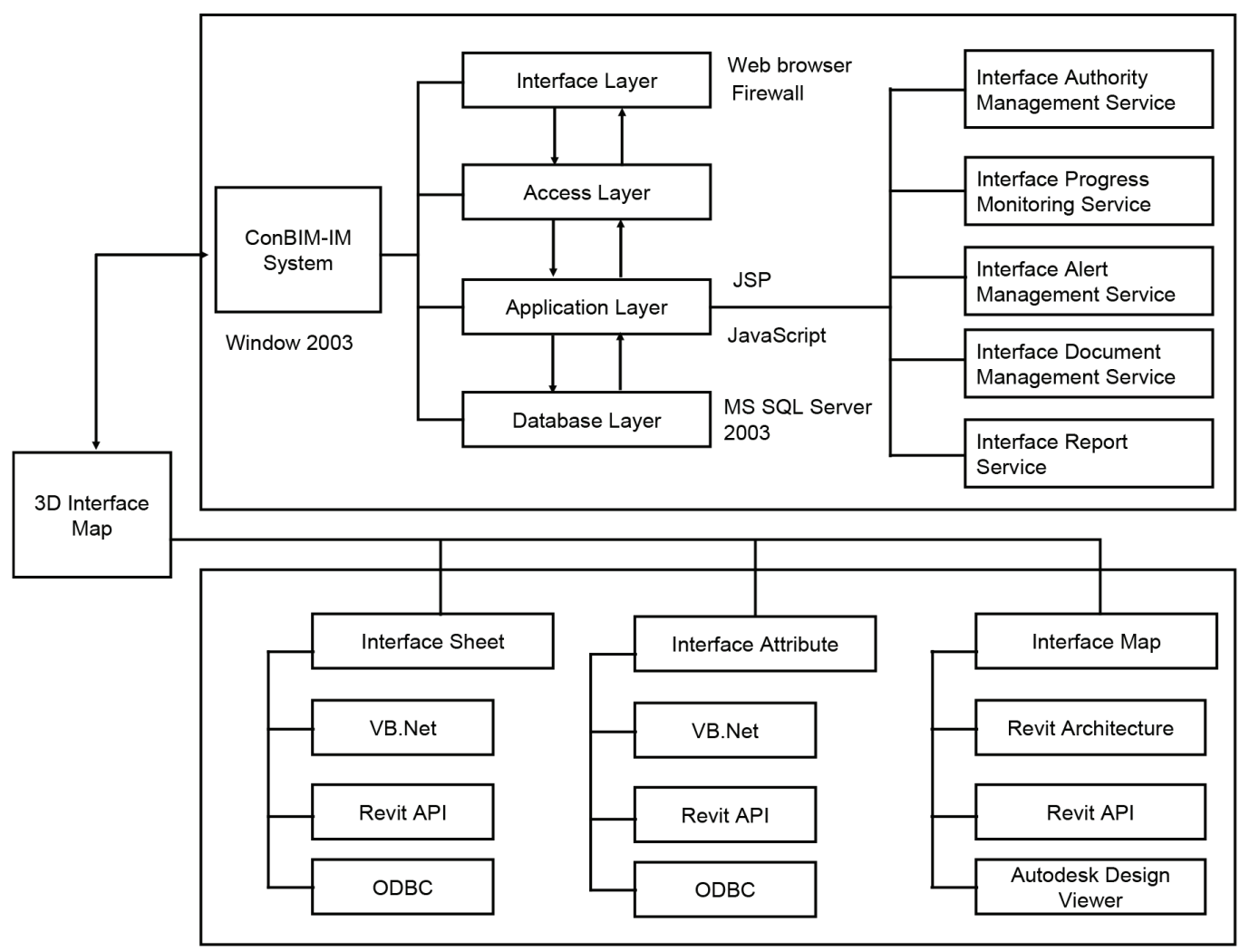

Fig. 5. Development framework of ConBIM-IM system 


\subsection{System modules}

This section demonstrates the implementation of ConBIM-IM system modules.

\subsubsection{Interface authority management module}

The interface authority management module is an access control mechanism preventing unauthorized users from entering the system or retrieving sensitive interface information. The ConBIM-IM system requires all project participants to register. To register, users provide a unique User ID and password for authentication. As interface information or reports required by different project participants and different interfaces vary, general contractors have different access permissions from other parties.

\subsubsection{Interface progress monitoring module}

This interface progress monitoring module tracks interface events. Additionally, project participants can share interface-related information regarding the current progress or status of an interface event. The progress monitoring module has an easy access option allowing participants to track and record online the information and status of an interface event. Furthermore, project participants can share the most recent interface event information and access all current and historical records for interface problems and solutions.

\subsubsection{Interface alert management module}

This module helps all project participants set up an alert service for monitoring and managing interfaces via e-mail and RSS feed. Dates related to notification of interface information are recorded systematically; thus, project participants can determine who is responsible for specific interface events. Furthermore, this module provides convenient access and a push-based function to help engineers respond to situations before interface events are tracked and others respond.

\subsubsection{Interface document management module}

The interface document management module allows users to download interface-related electronic documents from the ConBIM-IM system. Additionally, the module provides interface document edition management for interface tracking. This allows participants to manage, track, and organize BIM and interface-related files from a central location. This module also allows participants to determine when and by whom files have been accessed, downloaded, edited, or uploaded.

\subsubsection{Interface report module}

Users can easily access the interface report module to identify needs and analyse interface information. Authorized records for interfaces can be extracted and summarized for the interface-related reports. Furthermore, all interface reports can be presented on the web or extracted using commercially available software such as Microsoft Excel.

\section{Case study}

\subsection{Case description}

The following case involves a general contractor with 20 years of experience in constructing office buildings in Taiwan. The construction phase of this office-building project also involves five subcontractors and 16 suppliers. Furthermore, the general contractor wanted to take full advantage of IM to manage interfaces effectively and enhance construction project management. Therefore, the general contractor encouraged all participants to utilize the ConBIM-IM system to manage interfaces. The ConBIM-IM system was utilized in the office-building project to verify its efficacy and demonstrate its IM effectiveness. Figure 6 shows the flowchart of the process. Table 2 defines various roles played by project participants for interface management in the case project.

During the finding interfaces phase, all interfaces were identified by responsible participants or project managers. The engineer who initially identified the interfaces used Autodesk Revit Architecture or Revit MEP to create 3D interface maps and edited interface problems and issues related to construction/mechanical/electrical issues in interface sheets within the 3D interface maps. These interfaces included descriptions of construction/ mechanical/electrical problems, detailed situation descriptions, and explanations of problem solutions. Additionally, this engineer assigned interface participants in the 3D interface maps. Finally, this engineer submitted 3D interface maps to the ConBIM-IM system for approval. After approval was obtained from the project manager, related responsible participants recorded their experiences related to the construction/mechanical/electrical interfaces in the ConBIM-IM system. When the processed interface was tracked, the system showed the most recent status and result for each interface. Furthermore, engineers could access related interfaces directly by clicking on map units in the 3D interface maps. Furthermore, all interfaces were stored in the central database to avoid redundancy.

During the interface communication phase, four engineers communicated regarding selected interface issues in the ConBIM-IM system and shared the most recent interface information; that is, parties responsible for an interface provided explanations and comments in the ConBIM-IM system for others. One construction engineer used the ConBIM-IM system to discuss interfaces with two mechanical engineers. Another senior engineer used the ConBIM-IM system to request responses from two electrical engineers associated with the interface. The engineer identified problems and noted the interfaces (including descriptions, digital photos, and documentation) provided by the mechanical and electrical engineers. During the recording and tracking phase, all records of interface processes were saved and tracked continually. Interfaces not responded to or processed in the assigned time were tracked in red and pushed again by the ConBIM-IM system. Furthermore, project managers and 

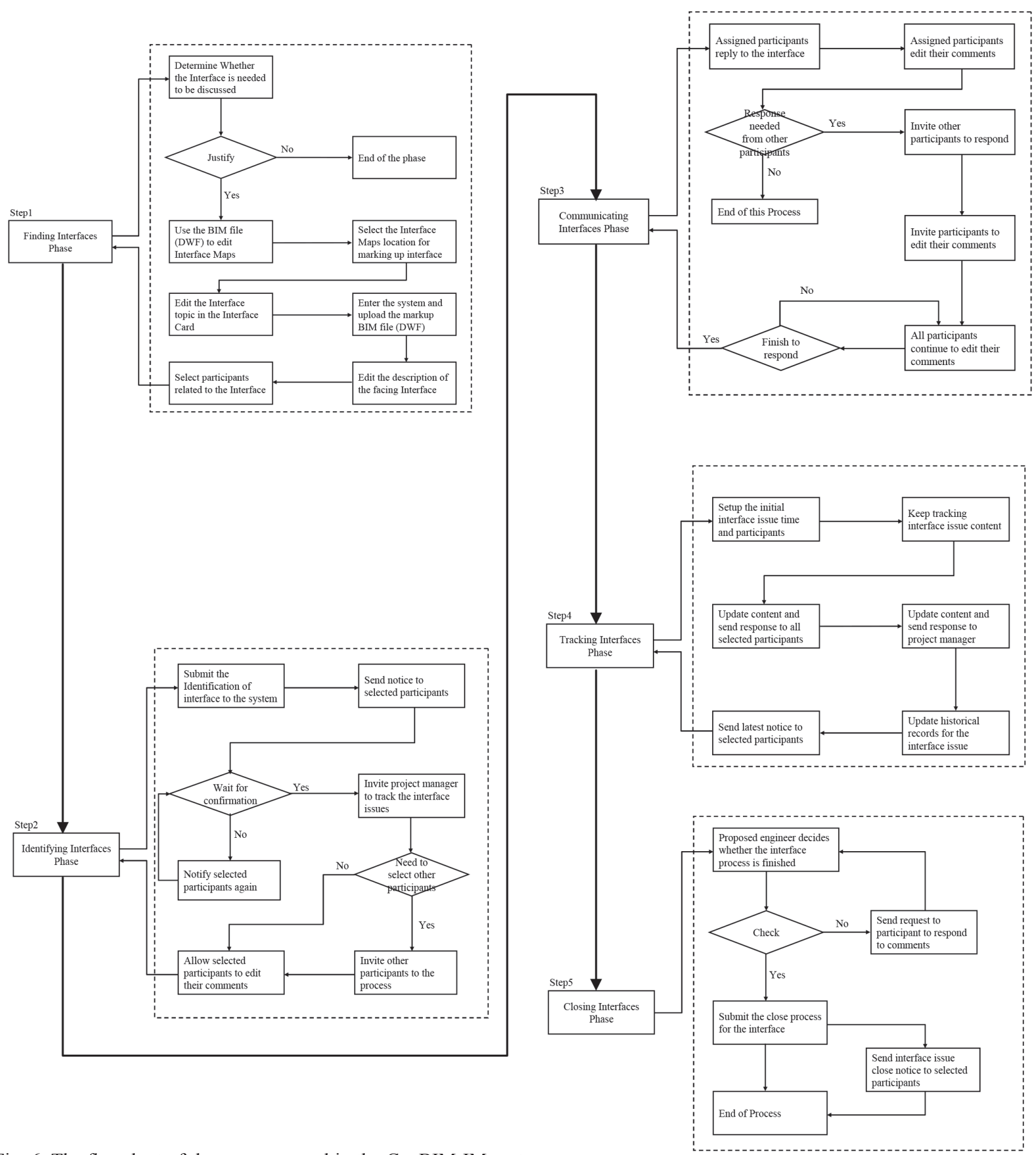

Fig. 6. The flowchart of the progress used in the ConBIM-IM system

Table 2. Description of roles of using ConBIM-IM system in the case project

\begin{tabular}{ll}
\hline Roles & \multicolumn{1}{c}{ Description } \\
\hline Interface initiator & Proposes an interface event to the project initially. \\
\hline Interface coordinator & Coordinates the implementation of an interface event. \\
\hline Interface manager & Approves interfaces during the IM process. \\
\hline BIM engineer & Creates/revises the development of BIM model of interface event. \\
\hline BIM manager & Approves BIM model during the IM process. \\
\hline
\end{tabular}




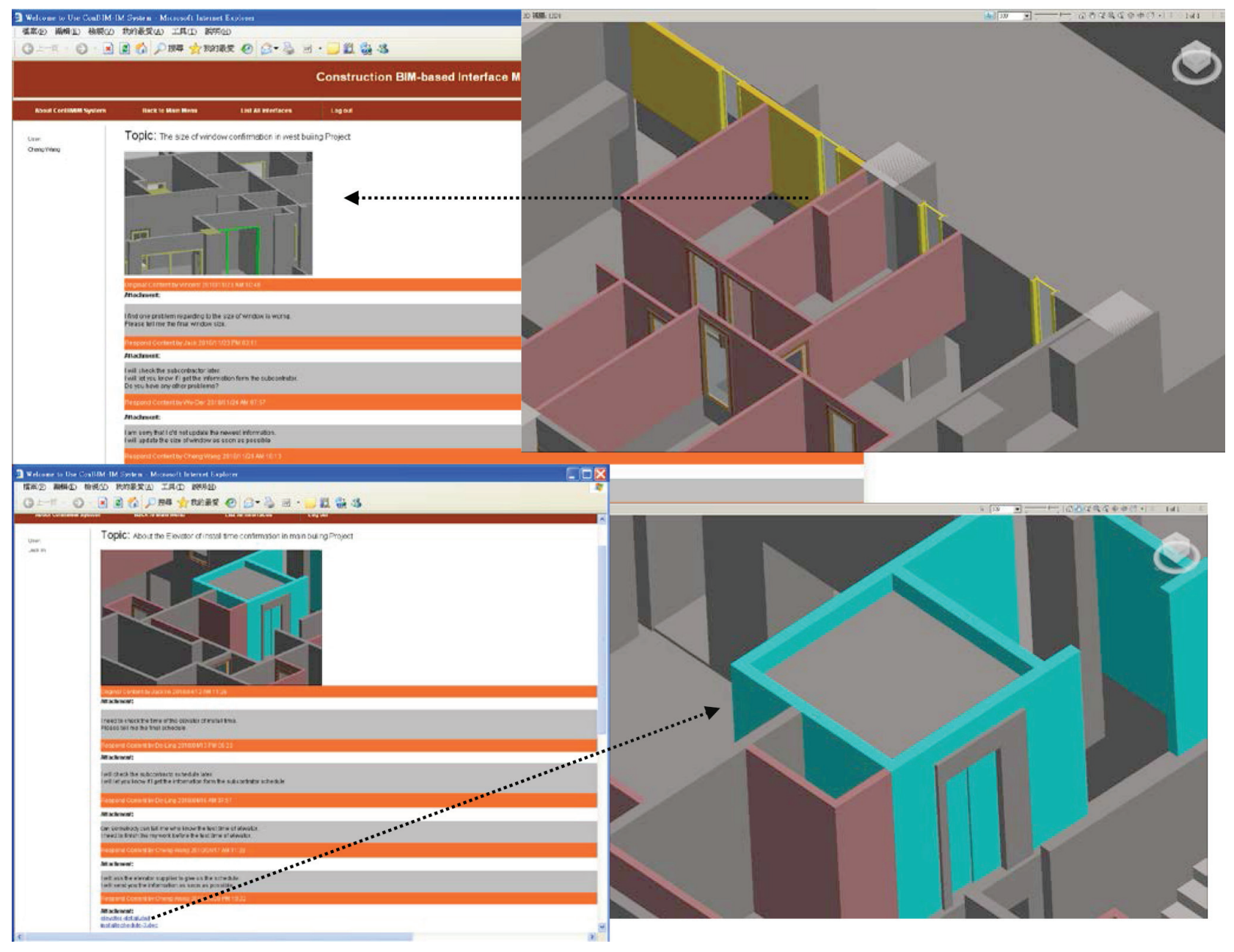

Fig. 7. The interfaces shared in the ConBIM-IM system

related participants could track and manage all completed or processed interfaces during the interface communication phase. The two electrical engineers began responding to the selected interfaces with comments and requests. Furthermore, one mechanical engineer provided solution feedback and offered suggestions for the applicable interface. For this interface, numerous requests and comments were shared among all participants during the during the tracking interface recording phase. Furthermore, the engineer that initially identified the interfaces encountered numerous problems and did not obtain solutions directly from selected interface participants. This engineer requested assistance from senior engineers involved in other similar projects to solve problems directly in the ConBIMIM system. After acquiring comments and assistance from all related participants, this engineer solved the interface problem and shared the interface result with others.

During the interface closing phase, this engineer closed the interface case and waited for project manager to confirm interface closure. Finally, the project manager confirmed interface closure. The interface status was updated in blue in 3D interface maps and the ConBIM-IM system after the approval process was complete; a notice and report were then transmitted to the project manager and authorized participants via e-mail and RSS. Figure 7 presents the interface-sharing management in the ConBIM-IM system.

\subsection{Field tests and results}

During the field test, case participants tracked and managed interfaces, changes, and conflicts. The general contractor handled the entire construction project through to completion. The mechanical, electrical, and plumbing subcontractors worked on building heating, cooling, and plumbing subprojects. The suppliers delivered building components and those required for installation subprojects. The ConBIM-IM system was installed on the general contractor's main server during the test. A user guide and five ConBIM-IM system workshops were held to demonstrate how to use the ConBIM-IM system. Furthermore, BIM software (Autodesk Revit Architecture and Autodesk Revit MEP) was applied as 3D interface map tools. Overall, field test results demonstrate that the ConBIM-IM system is an effective and user-friendly platform for construction IM. 

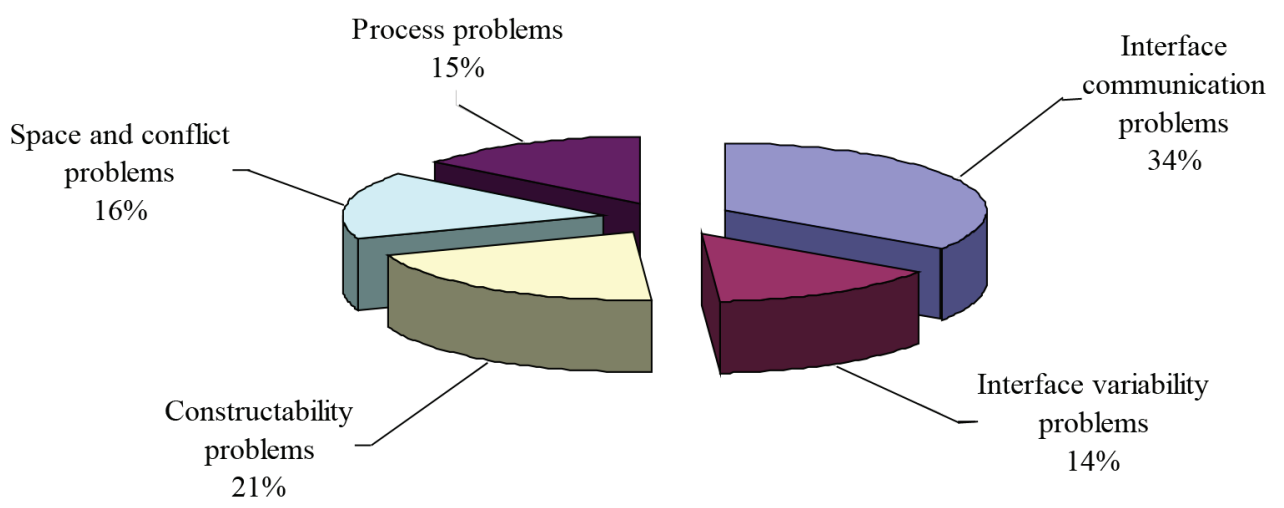

Fig. 8. Main interface problems solved by using ConBIM-IM system in the case project

The case study was a 10 -month construction project with approximately 1510 scheduled activities. There are five interface problem classifications in the ConBIM-IM system. The five interface problems types include process problem, interface communication, interface variability, space and conflict, and constructability problem. Figure 8 shows the main interface problems solved by using ConBIM-IM system in the case project according to the interface problem classifications selected by participants. There were 124 interface issues tracked by using ConBIM-IM system in the case study. Process problems comprised $15 \%$ of the problems. Interface communication comprised approximately $34 \%$ of the problems. Interface variability comprised $14 \%$ of the problems. Constructability comprised $21 \%$ of the problems, while problems of space and conflict comprised $16 \%$.

During the field test, verification and validation tests were performed to examine system function. The verification test determined whether the system operated correctly according to its design, while the validation test evaluated system utility. The verification test was performed by assessing whether the ConBIM-IM system performed tasks as specified in the system's design. During the validation test, selected case participants were asked to use the system; project teams then provided feedback via a questionnaire. The case participants consisted of two general contractor project managers with 15 years' experience, three senior engineers with 15 years' experience, four senior subcontractor engineers with 10 years' experience, and two general contractor junior engineers with two years' experience. To evaluate system function and user satisfaction with system capabilities, questionnaires were distributed. System users were asked to grade system usage, functionality, and capability separately, based on a comparison with the previous meeting approach on a five-point Likert scale, ranging from 1 for "not useful" to 5 for "very useful". Table 3 shows the results of the system testing from 11 case participants who used the ConBIM-IM system. Questionnaire results indicate that IM performance
Table 3. System evaluation result

\begin{tabular}{lc}
\hline System functionality & Mean score \\
\hline Ease of interface sharing & 4.5 \\
\hline Reliability & 4.4 \\
\hline Applicability to construction industry & 4.8 \\
\hline Use of system & Mean score \\
\hline Ease of use & 4.6 \\
\hline User interface & 4.5 \\
\hline Overall system usefulness & 4.3 \\
\hline System capability & Mean score \\
\hline Reduces variability & 4.2 \\
\hline Reduces unnecessary costs & 4.1 \\
\hline Reduces rework percentage & 4.3 \\
\hline Ease of finding interface information & 4.7 \\
\hline Improves interface problem tracking & 4.5 \\
\hline Reduces communication problems & 4.4 \\
\hline Enhances visual management & 4.7 \\
\hline Enhances interface tracking & 4.2 \\
\hline Reduces interface sharing problems & 4.7 \\
\hline
\end{tabular}

Note: the mean score is calculated from respondents' feedback on five scale questionnaire: 1 (strongly disagree), 2, 3, 4 and 5 (strongly agree).

was significantly improved by using the proposed system. Comments regarding possible improvements to the ConBIM-IM system were also obtained from respondents.

28 case participants were involved in the IM work of this test project. Only 11 case participants had access to the ConBIM-IM system directly during the case study. In the end of the final workshop, another questionnaire was presented to 28 case participants to answer questions about the effectiveness and applicability of the ConBIM-IM system in case study. Although those 17 case participants were involved in project IM work and did not personally use the ConBIM-IM system, they still 
understood the implementation of BIM-based IM and provided comments regarding to the application outcome of ConBIM-IM system. The following is the result based on the questionnaire.

Overall, case participants' feedback for the test was positive. Questionnaire results demonstrate that the primary advantages of the ConBIM-IM system are as follows: (1) The 3D interface maps provided clear visual representations facilitating identification of interface information and events related to 3D objects ( $93 \%$ agreed); (2) The 3D interface maps clearly identified available interface information and events relevant to tasks (86\% agreed); (3) Users tracked interface information and events easily and effectively with the BIM approach (94\% agreed).

The principal advantages of the ConBIM-IM system, based on above mentioned questionnaire results, are as follows. (1) The ConBIM-IM system allowed project managers to track and manage interface information and events during construction (93\% agreed); (2) The ConBIM-IM system allowed participants to collaborate and communicate regarding interfaces and changes through 3D interface maps (87\% agreed); (3) The ConBIM-IM system enabled participants to identify interfaces and changes to solve problems in advance ( $88 \%$ agreed); (4) The ConBIM-IM system enhanced interface and change management easily and effectively in the 3D CAD environment (90\% agreed).

\subsection{Limitations and barriers}

User feedback indicated that the primary barriers to using the ConBIM-IM system were as follows: (1) insufficient updated information related to various interfaces; (2) substantial amounts of time and assistance needed for engineers and managers to use BIM software to edit and update interface information; (3) most users were initially unfamiliar with BIM model in the beginning; and (4) unwillingness of few participants to share interface information.

The findings of this case study revealed several limitations of the ConBIM-IM system. The following are inherent problems recognized during the case study:

- It will be difficulty for new users to operate BIM model in ConBIM-IM system. In the beginning, some case participants were initially unfamiliar with BIM model. It usually takes time to learn the use of BIM model. In the case study, the use of BIM model initially took longer than current approach, since users needed time to find the corresponding BIM model and fill out the IM information in the ConBIM-IM system. After the user became familiar with the BIM model, the time of comparison of current approach and proposed system was almost the same during IM process.

- The IM is difficult to implement successfully within the 3D CAD environment if the BIM models don't exist for the purpose of construction management. Most general contractors don't want to spend the time and cost using BIM only for IM work of building projects. Another problem is that the ConBIMIM system can be used only on the construction site directly. The findings of case study indicated that most onsite engineers edited their interface when they returned to the site office. Most onsite engineers agreed that editing their interfaces at the jobsite using a smart phone or notebook in a Wi-Fi or $3 \mathrm{G}$ environment was inconvenient, based on the results of the case study. Therefore, onsite engineers have started to use tablet computers (such as iPads) for convenience. Case observations indicate that doing so improves the willingness of onsite engineers to apply the ConBIM-IM system and edit the interfaces directly at the jobsite.

- In the case study, overcoming the resistance of case participants to using the system during their work was important. Overcoming this resistance has been regarded as one of the major prerequisites for the successful implementation of a ConBIM-IM system. The final limitation of the ConBIM-IM system is that while it is highly effective in construction interface management, it cannot perform the project management work itself. Therefore, developing web-based project management systems for the construction industry requires the integration of ConBIM-IM with a webbased project management system. Doing so will be the goal of future work on ConBIM-IM system implementation.

The findings of this case study reveal a number of other limitations of the 3D-based interface maps approach. The following are four inherent problems based on the case study:

- This study demonstrates that 3D-based interface maps are effective in developing information systems to support construction interface management. 3D-based interface maps might not be suitable for all case participants, because some may not be used to web-based applications. Furthermore, some engineers and managers complained that they did not have sufficient time and assistance to edit and update the interface information. Another problem is that not all construction involved subcontractors and suppliers had the same attitude regarding interface management using a ConBIMIM system. The development of systems that satisfy all involved parties and the needs of the various case participants depends on advance analysis of the different parties' viewpoints. Future research must address how such a viewpoint analysis can be integrated into 3D-based interface maps.

- Case participants often cannot easily use the interface maps to edit interfaces when the original schedule plan is not clearly known or converted 
into 3D-based interface maps. This point concerning the implementation of 3D-based interface maps is critical. If a 3D-based interface map is too coarse, with only a few interface map elements and layers, then the case participants often will not be able to edit their interfaces effectively into the map elements. However, case participants may be confused about placing the interface into interface maps if the 3D-based interface maps are not clearly known or are too complicated. The second problem is that interfaces submitted by participants in the system lack content and are incomplete especially if case participants have a low willingness to use the system. Accordingly, the general contractor and parties involved in the project commonly supported IM. Models that elucidate how to translate an original schedule plan into a 3D-based interface map must be developed. Future research must address how an original schedule plan can integrate these models effectively into the 3D-based interface map methodology.

- Because the limited capacity of the PC and notebook, it is suggested that the BIM engineer create the DWF files in advance into the database for referring BIM models and handling the IM work. However, the file size of DWF will affect and impact the operation performance of ConBIM-IM system directly and obviously. When the DWF file is too large (more than 100MB), the DWF file may not be opened. Therefore, the main BIM model of the whole building will be exported and separated into many DWF files in the study. When the engineer executes IM work, the system only opens the necessary DWF file and refers the separated DWF files quickly for IM work.

- BIM model governance is indeed a very important factor for successful BIM-based IM. When using BIM as communication tools of IM, it is necessary and important to obtain the latest version of the BIM model during the process of IM. Using the old BIM will increase many IM problems if used for the discussion. Therefore, it is necessary and important for project participants to confirm and obtain the latest version of BIM model before the IM process. In the study, an API subsystem is developed to allow project participants to confirm and obtain the latest version of the BIM model to communicate interfaces with others. Furthermore, it is necessary to update the BIM model again if the final result is confirmed and requires changes to the model. The responsible BIM engineer will update the BIM model and re-notify all related participants for notification of the latest version of BIM model. Without the appropriate governance mechanism to confirm and manage BIM model, there will be many problems in the implementation of BIMbased interface management.

\section{Conclusions}

The application of IM integrated with the BIM approach for building projects during the construction phase is discussed in this work. This study implements the novel ConBIM-IM system for all project participants as an interface-sharing platform. Through a web-based environment, the ConBIM-IM system minimizes ineffective communication of interface information to engineers. The ConBIMIM system provides insight into factors impacting IM activities, which in turn assists participants in managing interface events to improve construction management performance. The collection of interface events and problems by the ConBIM-IM system allows project participants and engineers to track and manage the most recent interfacerelated information in the 3D CAD environment.

The ConBIM-IM system tracks interface events, problem descriptions, and solutions using $3 \mathrm{D}$ interface maps. The 3D interface maps illustrate interface events, problem descriptions, and solutions in 3D representations. Notably, BIM is a highly promising means of enhancing IM and identifying interface information relevant to both tasks and projects. Notably, BIM integrates $3 \mathrm{D}$ objects comprising building design by incorporating external factors, such as interface events, interface descriptions, and interface conditions, into a database that functions as the sole integrated source for all construction interface-related information.

Finally, the proposed ConBIM-IM system is applied to a case study of a building project in Taiwan to verify its efficacy and demonstrate its IM effectiveness. Case study results demonstrate that the ConBIM-IM system allows project participants to identify, track, coordinate, and access construction interfaces in construction projects. The case study also highlights the need to improve IM during the construction phase. Integrating web-based technologies and the BIM approach is promising for improving IM during the construction phase. Overall, field test results indicate that the proposed ConBIM-IM system is an effective and user-friendly platform for construction IM.

The following recommendations are based on user feedback: (1) Policy and strategy must be considered to encourage use of the ConBIM-IM system and BIM software because effective use requires changes to almost every aspect of a firm's business; (2) Considerable effort is required to update interface information related to interface events during a project; (3) The implementation of BIM integrated with IM requires top management and onsite project manager executive support to succeed; (4) It will be convenient for onsite engineers to access the ConBIM-IM system directly by using tablet computers on the construction site; (5) Further training and workshops for the ConBIM-IM system and BIM software are needed for all users; (6) The ConBIM-IM system and BIM approach should be integrated with webbased project management tools in the future. 
The following recommendations regarding use of the BIM approach are based on user feedback: (1) The successful BIM adoption should be supported by top management in a firm; (2) Further effort is required to train participants in using BIM software to model interfaces via 3D interface maps; (3) Further effort and time are required to overcome unwillingness to adopt BIM software as a replacement for the traditional $2 \mathrm{D}$ approach; (4) The one of onsite engineers should be a BIM related engineer who is familiar with how the BIM models are built and utilized for IM; (5) Initial case study results should be used to educate users about BIM software adoption, and additional staff training is needed.

\section{Acknowledgements}

The authors would like to acknowledge the National Science Council, Taiwan, for financially supporting this work and express our appreciation to the D-F Construction Inc. for assistance in the system design and interviews, and to the experts and engineers of the owner of the project for providing useful data, valuable information, and helpful comments during system design and development.

\section{References}

Al-Hammad, A. 2000. Common interface problems among various construction parties, Journal of Performance of Constructed Facilities 14(2): 71-74.

http://dx.doi.org/10.1061/(ASCE)0887-3828(2000)14:2(71)

Azhar, S. 2011. Building Information Modeling (BIM): trends, benefits, risks, and challenges for the AEC industry, Leadership and Management in Engineering 11(3): 241-252. http://dx.doi.org/10.1061/(ASCE)LM.1943-5630.0000127

Azimi, R.; Lee, S. H.; AbouRizk, S. M.; Alvanchi, A. 2011. A framework for an automated and integrated project monitoring and control system for steel fabrication projects, Automation in Construction 20(1): 88-97. http://dx.doi.org/10.1016/j.autcon.2010.07.001

Barlish, K.; Sullivan, K. 2012. How to measure the benefits of BIM-A case study approach, Automation in Construction 24: 605-613. http://dx.doi.org/10.1016/j.autcon.2012.02.008

Becerik-Gerber, B.; Kensek, K. 2010. Building information modeling in architecture, engineering, and construction: emerging research directions and trends, Journal of Professional Issues in Engineering Education and Practice 136(3): 139-147.

http://dx.doi.org/10.1061/(ASCE)EI.1943-5541.0000023

Becerik-Gerber, B.; Rice, S. 2010. The perceived value of building information modeling in the US building industry, ITCON 15: 185-201 [online], [cited 20 May 2011]. Available from Internet: http://www.itcon.org

Chan, W. T.; Chen, C.; Messner, J. I.; Chua, D. K. H. 2005. Interface management for China's build-operate-transfer projects, Journal of Construction Engineering and Management 131(6): 645-655.

http://dx.doi.org/10.1061/(ASCE)0733-9364(2005)131:6(645)

Chau, K.; Anson, M.; Zhang, J. 2004. Four-dimensional visualization of construction scheduling and site utilization, Journal of Construction Engineering and Management 130(4): 598-606.

http://dx.doi.org/10.1061/(ASCE)0733-9364(2004)130:4(598)
Chen, Q.; Reichard, G.; Beliveau, Y. 2008. Multiperspective approach to exploring comprehensive cause factors for interface issues, Journal of Construction Engineering and Management 134(6): 432-441.

http://dx.doi.org/10.1061/(ASCE)0733-9364(2008)134:6(432)

Chen, Q.; Reichard, G.; Beliveau, Y. 2010. Object model framework for interface modeling and IT-oriented interface management, Journal of Construction Engineering and Management 136(2): 187-198. http://dx.doi.org/10.1061/(ASCE)CO.1943-7862.0000120

Chen, Q; Reichard, G.; Beliveau, Y. 2007. Interface management - a facilitator of lean construction and agile project management, in Proc. of the Fifteenth Annual Conference of the International Group for Lean Construction (IGLC-15), 21-25 July 2007, Michigan, 57-66.

Chua, D. K. H.; Godinot, M. 2006. Use of a WBS matrix to improve interface management in projects, Journal of Construction Engineering and Management 132(1): 67-79.

http://dx.doi.org/10.1061/(ASCE)0733-9364(2006)132:1(67)

Clough, R. H.; Sears, G. A.; Sears, S. K. 2000. Construction project management. $4^{\text {th }}$ ed. New York: Wiley. $360 \mathrm{p}$.

$\mathrm{CRC}$ for Construction Innovation 2010. Adopting BIM for facilities management: solutions for managing the Sydney opera house [online], [cited 28 March 2010]. Available from Internet: http://eprints.qut.edu.au/27582/1/27582.pdf 20078

Design Web Format Wikipedia [online], [accessed 1 March 2012]. Available from Internet: http://en.wikipedia.org/wiki/Design_Web_Format

Ding, L. Y.; Zhou, Y.; Luo, H. B. Wu, X. G. 2012. Using nD technology to develop an integrated construction management system for city rail transit construction, Automation in Construction 21(7): 64-73. http://dx.doi.org/10.1016/j.autcon.2011.05.013

Dossick, C. S.; Neff, G. 2010. Organizational divisions in BIMenabled commercial construction, Journal of Construction Engineering and Management 136(4): 459-467. http://dx.doi.org/10.1061/(ASCE)CO.1943-7862.0000109

Eastman, C.; Teicholz, P.; Sacks, R.; Liston, K. 2008. BIM handbook: A guide to building information modeling for owners, managers, designers, engineers and contractors. Hoboken, NJ: Wiley. 640 p. http://dx.doi.org/10.1002/9780470261309

Eddy, K.; Bradley, N. 2008. Green BIM: successful sustainable design with building information modeling. Hoboken, NJ: Wiley. $241 \mathrm{p}$.

Elbeltagi, E.; Dawood, M. 2011. Integrated visualized time control system for repetitive construction projects, Automation in Construction 20(7): 940-953. http://dx.doi.org/10.1016/j.autcon.2011.03.012

Evans, G. N., et al. 1997. Organizing for improved construction interfaces, Innovation in Civil and Construction Engineering 49: 207-212. http://dx.doi.org/10.4203/ccp.49.6.5

Fox, S.; Hietanen, J. 2007. Interorganizational use of building information models: potential for automational informational and transformational effects, Construction Management and Economics 25(3): 289-296.

http://dx.doi.org/10.1080/01446190600892995

Fu, C.; Aouad, G.; Lee, A.; Ponting, A.; Wu, S. 2006. IFC model viewer to support $\mathrm{nD}$ model application, Automation in Construction 15(2): 178-185. http://dx.doi.org/10.1016/j.autcon.2005.04.002

Goedert, J. D.; Meadati, A. G. F. 2008. Integrating construction process documentation into building information modeling, Journal of Construction Engineering and Management 134(7): 509-516.

http://dx.doi.org/10.1061/(ASCE)0733-9364(2008)134:7(509)

Golparvar-Fard, M.; Peña-Mora, F.; Arboleda, C. A.; Lee, S. H. 2009. Visualization of construction progress monitoring 
with 4D simulation model overlaid on time-lapsed photographs, Journal of Computing in Civil Engineering 11: 391-404.

http://dx.doi.org/10.1061/(ASCE)0887-3801(2009)23:6(391)

Gould, F.; Joyce, N. E. 2008. Construction project management. $3^{\text {rd }}$ ed. Prentice Hall. 357 p.

Hajdasz, M. 2008. Visualizing simulated monolithic construction processes, Journal of Civil Engineering and Management 14(4): 295-306. http://dx.doi.org/10.3846/1392-3730.2008.14.29

Hardin, B. 2009. BIM and construction management: proven tools, methods, and workflows. New Jersey: John Wiley \& Sons. 364 p.

Hartmann, T.; Meerveld, H. V.; Vossebeld, N.; Adriaanse, A. 2012. Aligning building information model tools and construction management methods, Automation in Construction 22: 605-613.

http://dx.doi.org/10.1016/j.autcon.2011.12.011

Healy, P. 1997. Interfaces project management: getting the job done on time and in budget. Butterworth-Heinemann, Port Melbourne, Vic. 299 p.

Isikdag, U.; Underwood, J. 2010. Two design patterns for facilitating building information model-based synchronous collaboration, Automation in Construction 19(5): 544-553. http://dx.doi.org/10.1016/j.autcon.2009.11.006

Jardim-Goncalves, R.; Grilo, A. 2010. SOA4BIM: putting the building and construction industry in the Single European Information Space, Automation in Construction 19(4): 388-397. http://dx.doi.org/10.1016/j.autcon.2009.11.009

Jeong, Y. S.; Eastman, C. M.; Kaner, R. S. 2009. Benchmark test for BIM data exchanges of precast concrete, Automation in Construction 18(4): 469-484.

http://dx.doi.org/10.1016/j.autcon.2008.11.001

Jung, Y.; Joo, M. 2011. Building information modelling (BIM) framework for practical implementation, Automation in Construction 20(2): 126-133. http://dx.doi.org/10.1016/j.autcon.2010.09.010

Kaner, I.; Sacks, R.; Kassian, W.; Quitt, T. 2008. Case studies of BIM adoption for precast concrete design by midsized structural engineering firms, ITCON 13: 303-323 [online], [cited 21 June 2011]. Available from Internet: http://www.itcon.org

Klein, L.; Li, N.; Becerik-Gerber, B. 2012. Imaged-based verification of as-built documentation of operational buildings, Automation in Construction 21(1): 161-171. Laan, J.; Wildenburg, L.; Kleunen, P. 2000. Dynamic interface management in transport infrastructure project, in Proc. of $2^{\text {nd }}$ European Systems Engineering Conference, September 2000, Munich, Germany.

Lee, G.; Park, H. K.; Won, J. 2012a. D3 city project - economic impact of BIM-assisted design validation, Automation in Construction 22: 577-586. http://dx.doi.org/10.1016/j.autcon.2011.12.003

Lee, S. I.; Bae, J. S.; Cho, Y. S. 2012b. Efficiency analysis of set-based design with structural building information modeling (S-BIM) on high-rise building structures, Automation in Construction 23: 20-32. http://dx.doi.org/10.1016/j.autcon.2011.12.008

Lee, J. K.; Lee, J.; Jeong, Y.-S.; Sheward, H.; Sanguinetti, P.; Abdelmohsen, S.; Eastman, C. M. 2012c. Development of space database for automated building design review systems, Automation in Construction 24: 203-212. http://dx.doi.org/10.1016/j.autcon.2012.03.002

Leite, F.; Akcamete, A.; Akinci, B.; Atasoy, G.; Kiziltas, S. 2011. Analysis of modeling effort and impact of different levels of detail in building information models, Automation in Construction 20(5): 601-609. http://dx.doi.org/10.1016/j.autcon.2010.11.027
Li, G.; Ding, L.; Wang, J. 2006. Construction project control in virtual reality: a case study, Journal of Applied Science 3(13): 2724-2732.

Lin, Y.-C. 2009. Developing construction network-based interface management system, in Proc. of the 2009 Construction Research Congress, 4-7 April 2009, Seattle Marriott Waterfront, Seattle, USA, 477-486.

Liston, K. M.; Fischer, M.; Kunz, J. 1998. 4D annotator: a visual decision support tool for construction planners, Journal of Computing in Civil Engineering, 330-341.

Ma, Z. Y.; Shen, Q. P.; Zhang, J. P. 2005. Application of 4D for dynamic site layout and management of construction projects, Automation in Construction 14(3): 369-381. http://dx.doi.org/10.1016/j.autcon.2004.08.011

Manning, R.; Messner, J. 2008. Case studies in BIM implementation for programming of healthcare facilities, ITCON 13: 446-457 [online], [cited 27 March 2011]. Available from Internet: http://www.itcon.org

Matta, C.; Kam, C. 2010. The GSA'sBIM Pilot Program [online]. Presentation by GSA PBS Office of the Chief Architect [cited 21 March 2010]. Available from Internet: http://bim.arch.gatech.edu/data/reference/gsaBIM.pdf

Morris, M. D. 1983. Managing project interfaces-key points for project success, in Project management handbook. New York: Van Nostrand Reinhold, 407-446.

Moum, A. 2010. Design team stories exploring interdisciplinary use of 3D object models in practice, Automation in Construction 19(5): 554-569. http://dx.doi.org/10.1016/j.autcon.2009.11.007

NBIMS. 2007. National building information modeling standard Part-1: Overview, Principles and Methodologies, US National Institute of Building Sciences Facilities Information Council, BIM Committee [online], [cited 19 Sep 2011]. Available from Internet: http://www.wbdg.org/pdfs/NBIMSv1_p1.pdf

Pavitt, T. C.; Gibb, A. G. F. 2003. Interface management within construction: in particular, building façade, Journal of Construction Engineering and Management 129(1): 8-15.

http://dx.doi.org/10.1061/(ASCE)0733-9364(2003)129:1(8)

Redmond, A.; Hore, A.; Alshawi, M.; West, R. 2012. Exploring how information exchanges can be enhanced through cloud BIM, Automation in Construction 24: 175-183. http://dx.doi.org/10.1016/j.autcon.2012.02.003

Ren, Y.; Skibniewski, M. J.; Jiang, S. 2012. Building information modeling integrated with electronic commerce material procurement and supplier performance management system, Journal of Civil Engineering and Management 18(5): 642-654. http://dx.doi.org/10.3846/13923730.2012.719835

Sacks, R.; Barak, R. 2010. Teaching building information modeling as an integral part of freshman year civil engineering education, Journal of Professional Issues in Engineering Education and Practice 136(1): 30-38. http://dx.doi.org/10.1061/(ASCE)EI.1943-5541.0000003

Sacks, R.; Kaner, I.; Eastman, C. M.; Jeong, Y. S. 2010. The rosewood experiment-building information modeling and interoperability for architecture precast facades, Automation in Construction 19(4): 419-432. http://dx.doi.org/10.1016/j.autcon.2009.11.012

Schlueter, A.; Thesseling, F. 2009. Building information model based energy/exergy performance assessment in early design stages, Automation in Construction 18(2): 153-163. http://dx.doi.org/10.1016/j.autcon.2008.07.003

Senthilkumar, V.; Varghese, K.; Chandran, A. 2010. A webbased system for design interface management of construction projects, Automation in Construction 19(2): 197-212. http://dx.doi.org/10.1016/j.autcon.2009.10.007 
Shen, W.; Shen, Q.; Sun, Q. 2012. Building information modeling-based user activity simulation and evaluation method for improving designer-user communications, Automation in Construction 21: 148-160. http://dx.doi.org/10.1016/j.autcon.2011.05.022

Shen, Z.; Issa, R. 2010. Quantitative evaluation of the BIM assisted construction detailed cost estimates, ITCON 15: 234-257 [online], [cited 22 May 2011]. Available from Internet: http://www.itcon.org

Shokri, S.; Safa, M.; Haas, C. T.; Haas; R. C. G.; Maloney, K.; MacGillivray, S. 2012. Interface management model for mega capital projects, in Proc. of the 2012 Construction Research Congress, 21-23 May 2012, Purdue University, Indiana, United States, 447-456. http://dx.doi.org/10.1061/9780784412329.045

Siao, F. C.; Lin, Y. C. 2012. Enhancing construction interface management using multilevel interface matrix, Journal of Civil Engineering and Management 18(1): 133-144. http://dx.doi.org/10.3846/13923730.2012.657368

Siao, F. C.; Shu, Y. C.; Lin, Y. C. 2009. Interface management practice in Taiwan construction project, in Proc. of the $28^{\text {th }}$ International Symposium on Automation and Robotics in Construction, 29 June - 2 July 2011, Korea, Seoul, 947-952.

Staub-French, S.; Khanzode, A. 2007. 3D and 4D modeling for design and construction coordination: issues and lessons learned, ITCON 12: 381-407 [online], [cited 5 June 2011]. Available from Internet: http://www.itcon.org

Stuckenbruck, L. C. 1983. Integration: the essential function of project management, in Cleland, D. I.; King, W. R. (Eds.). Project management handbook. New York: Van Nostrand Reinhold, 207-232.

Succar, B. 2009. Building information modelling framework: a research and delivery foundation for industry stakeholders, Automation in Construction 18(3): 357-375. http://dx.doi.org/10.1016/j.autcon.2008.10.003
Tse, T. K.; Wong, K. A.; Wong, K. F. 2005. The utilisation of building information models in $\mathrm{nD}$ modelling: a study of data interfacing and adoption barriers, ITCON 10: 85-110 [online], [cited 16 May 2011]. Available from Internet: http://www.itcon.org

Underwood, J.; Isikdag, U. 2010. Handbook of research on building information modeling and construction informatics: concepts and technologies. IGI Global. $567 \mathrm{p}$.

Vainiunas, P.; Popovas, V.; Jarmolajev, A. 2011. Non-linear 3D modelling of RC slab punching shear failure, Journal of Civil Engineering and Management 10(4): 311-316. http://dx.doi.org/10.1080/13923730.2004.9636324

Vanlande, R.; Nicolle, C.; Cruz, C. 2008. IFC and building lifecycle management, Automation in Construction 134(7): 70-78. http://dx.doi.org/10.1016/j.autcon.2008.05.001

Whyte, J.; Bouchlaghem, N.; Thorpe, A. 2002. IT implementation in the construction organization, Engineering, Construction and Architectural Management 9(5-6): 371-377. http://dx.doi.org/10.1108/eb021231

Whyte, J.; Bouchlaghem, N.; Thorpe, A.; McCaffer, R. 1999. A survey of CAD and virtual reality within the house building industry, Engineering, Construction and Architectural Management 6(4): 371-379. http://dx.doi.org/10.1108/eb021125

Xudong, Z.; Jie, T. 2007. Building information modeling based on intelligent parametric technology, Frontiers of Architecture and Civil Engineering in China 1(3): 367-370. http://dx.doi.org/10.1007/s11709-007-0049-4

Zhang, J. P.; Hu, Z. Z. 2011. BIM- and 4D-based integrated solution of analysis and management for conflicts and structural safety problems during construction: 1 . Principles and methodologies original research article, Automation in Construction 20(2): 155-166. http://dx.doi.org/10.1016/j.autcon.2010.09.013

Zhou, W.; Whyte, J.; Sacks, R. 2012. Construction safety and digital design: a review, Automation in Construction 22: 102-111. http://dx.doi.org/10.1016/j.autcon.2011.07.005

Yu-Cheng LIN. Associate Professor of Construction Engineering and Management at the Department of Civil Engineering of the National Taipei University of Technology. He received the MS degree in the Construction Management program of Civil Engineering from the Polytechnic University, New York, USA and received PhD degree from the National Taiwan University in Taiwan (2004). He has published several articles and papers on the role of academic support service in computer-based construction project management. His current research interests include construction knowledge management, project interface management, building information modelling, web-based project management system, IT technology application, automation, BIM related topics. 